\title{
Barriers to utilization of eye care services in the upper east region, Ghana
}

\begin{abstract}
The aim of the study was to determine the barriers to utilization of eye care services in the Upper East region of Ghana. A descriptive cross-sectional study in which 350 participants were randomly sampled from 8 district capitals and one settlement. These locations were selected for the study because an eye care facility was located in each of them. Interview of participants was conducted using structured questionnaires. Majority $(53.71 \%)$ of the participants were females. Forty percent $(40.00 \%)$ of the participants had not sought eye care in the last three years. There was no statistically significant difference in gender utilization of eye care services $(\mathrm{p}=0.204)$. The major barriers to utilization of eye care services identified were social engagement/other priorities, ability to perform daily task despite condition, cost of service and transportation, distance to eye care facility and the lack of knowledge of the availability of eye care services and treatment. This finding suggests that attitude, poverty and lack of awareness are major barriers to eye care utilization in the Upper East region. The importance of public education in the region and a health insurance with a wider coverage cannot be overemphasized.
\end{abstract}

Keywords: barriers; utilization; eye care; region; social-related; financial
Volume 7 Issue 6 - 2017

\author{
Prince Kwaku Akowuah,' Merepa SS,' \\ Abazele AS,' Gyamfi JA,' Adjei-Anang J,' \\ Djeagbo PT,' Gyekye-Darko NA' \\ 'Department of Optometry and Visual Science, College of \\ Science, Kwame Nkrumah University of Science and Technology, \\ Ghana \\ ${ }^{2}$ Department of Optometry and Visual Science, University of \\ Cape Coast, Ghana
}

\begin{abstract}
Correspondence: Prince Kwaku Akowuah, Department of Optometry and Visual Science, Kwame Nkrumah University of Science and Technology, Kumasi, Ghana Email prince.k.akowuah@gmail.com
\end{abstract}

Received: October 29, 2017 | Published: November 16, 2017

\section{Introduction}

A recent report by the World Health Organization (WHO) estimated the number of people visually impaired worldwide to be 285 million: 39 million are blind and 246million have low vision. Eighty percent $(80 \%)$ of the 285 million visual impairment can be prevented or cured and about $90 \%$ of the global visual impairment is found in low income settings. ${ }^{1}$ In efforts to tackle the global burden of visual impairment, the "Universal Eye Health: a Global Action Plan 2014-2019", a follow up to the VISION 2020 initiative was adopted by member states at the World Health Assembly in 2013, with the vision of "A world in which nobody is needlessly visually impaired, where those with unavoidable vision loss can achieve their full potential and where there is universal access to comprehensive eye care services". ${ }^{2}$. Two of the key factors to the realization of the vision of the "Universal Eye Health: a Global Action Plan 2014-2019" are eye care services and their utilization. Reports from previous studies show that even when eye care services are available, they are generally under-used by the potential beneficiaries. ${ }^{3,4}$ Utilization of eye care services, like other health care services is influenced by a number of factors such as awareness, quality of service, the cost of service, distance from service, escort needed and fear. The study by Ebeigbe and OvenseriOgbomo reported factors such as gender, poverty and ignorance as major barriers to eye care services utilization in rural communities. ${ }^{5}$ The aim of the study was to determine barriers to utilization of eye care services in the Upper East region of Ghana.

\section{Materials and methods}

The study was conducted in the Upper East Region of Ghana. According to the Population and Housing Census in 2010, the Upper East region is $79 \%$ rural and $21 \%$ urban. The region comprises 2 municipalities and 11 districts. ${ }^{6}$ The study was a descriptive crosssectional study in which 350 participants were randomly sampled from 8 district capitals and one settlement. The locations for the study were selected using purposive sampling (an eye care facility was located in each of them). Random sampling was used in selecting the study participants. The participants were interviewed with a structured questionnaire after the details of the study were thoroughly explained to them. In the barriers to eye care section of the questionnaire, participants were allowed to choose more than one response if it applies. For the purposes of this study, eye care service was defined as that delivered in an orthodox health care facility. The data was analyzed using the Statistical Package for Social Scientists (SPSS) software version 20.0 and Microsoft Excel (2010). Proportional data were compared using Chi - Square test. At 95\% confidence interval, $\mathrm{p}$ - values $<0.05$ were considered to be significant.

\section{Results}

Majority (53.71\%) of the participants were female and 162 (46.29\%) were males. Age range of participants was 16-82 years with a mean age of 43.7 years. Majority $(60.00 \%)$ of the participants had sought eye care in the last three years (labelled as seekers) while $140(40.00 \%)$ of the participants had not sought eye care in the last 3 years (labelled as non-seekers). Of the 210 eye care seekers within the last three years, 107 (50.95\%) of them were females. There was no statistically significant difference in gender utilization of eye care services $(\mathrm{p}=0.204)$ (Tables $1 \& 2)$.

Table I Demographics of Participants

\begin{tabular}{llll}
\hline Age/Gender & Male [N(\%)] & Female [N(\%)] & Total [N(\%)] \\
\hline$<20$ & $15(4.29)$ & $18(5.14)$ & $33(9.43)$ \\
$21-30$ & $35(10.00)$ & $31(8.86)$ & $66(18.86)$ \\
$31-40$ & $20(5.71)$ & $37(10.57)$ & $57(16.28)$ \\
$41-50$ & $25(7.14)$ & $27(7.71)$ & $52(14.85)$ \\
$51-60$ & $23(6.57)$ & $22(6.29)$ & $45(12.86)$ \\
$61-70$ & $22(6.29)$ & $25(7.14)$ & $47(13.43)$ \\
$>71$ & $22(6.29)$ & $28(8.00)$ & $50(14.29)$ \\
Total & $162(46.29)$ & $188(53.71)$ & $350(100)$ \\
\hline
\end{tabular}


Table 2 Barriers to Utilization of Eye Care Services

\begin{tabular}{|c|c|c|c|c|}
\hline Barriers & & Males [n(\%)] & Females $[n(\%)]$ & Total $[n(\%)]$ \\
\hline \multirow{3}{*}{ Financial } & Cost of service & $29(8.29 \%)$ & $4 \mathrm{I}(1 \mathrm{I} .7 \mathrm{I} \%)$ & $70(20.00 \%)$ \\
\hline & Transportation & $44(\mid 2.57 \%)$ & $54(15.43 \%)$ & $98(28.00 \%)$ \\
\hline & Social engagement/ other priorities & $86(24.57 \%)$ & $72(20.57 \%)$ & $158(45.14 \%)$ \\
\hline \multirow{2}{*}{ Social } & Need for escort & $26(7.43 \%)$ & $32(9.14 \%)$ & $58(16.57 \%)$ \\
\hline & Use of traditional/home remedy & $8(2.29 \%)$ & $\mathrm{II}(3.14 \%)$ & $19(5.43 \%)$ \\
\hline \multirow{3}{*}{ Service - related } & Waiting time & $37(10.57 \%)$ & $32(9.14 \%)$ & $69(19.71 \%)$ \\
\hline & Distance to eye care facility & $34(9.71 \%)$ & $74(21.14 \%)$ & $108(30.85 \%)$ \\
\hline & No perceived need & $48(|3.7| \%)$ & $20(5.71 \%)$ & $68(19.42 \%)$ \\
\hline \multirow{3}{*}{ Attitude-related } & Ability to perform daily task with condition & $50(\mid 4.29 \%)$ & $63(18.00 \%)$ & $113(32.29 \%)$ \\
\hline & Fear & $20(5.71 \%))$ & $12(3.43 \%)$ & $32(9.14 \%)$ \\
\hline & Acceptance of condition & $18(5.14 \%)$ & $46(13.14)$ & $64(18.28 \%)$ \\
\hline \multirow{2}{*}{ Awareness } & No knowledge of eye care & $38(10.86 \%)$ & $44(12.57 \%)$ & $82(23.43 \%)$ \\
\hline & Thought nothing could be done & $23(6.57 \%)$ & $28(8.00 \%)$ & $5 \mathrm{I}(14.57 \%)$ \\
\hline
\end{tabular}

\section{Discussion}

Majority $(60.00 \%)$ of the participants had sought eye care services for at least once in the last three years before the study. This demonstrates a generally good eye care seeking behaviour among the participants. This finding however conflicts with those of Ebeigbe and Ovenseri-Ogbomo, Robin et al. and Olusanya et al., ${ }^{7-9}$ in which majority of the participants had previously not gone for an eye examination in a hospital before. There was no statistically significant difference in gender utilization of eye care services $(p=0.204)$, even though female participants were more than male participants. This is consistent with the study by Robin et al.. ${ }^{8}$. It however contrasts with the studies by Ebeigbe and Ovenseri-Ogbomo and Palagyi et al. ${ }^{7,10}$ who reported women were more likely to seek eye care services than men.

There was an overwhelming predominance of social-related barriers compared to service-related barriers. Previous studies. ${ }^{11-14}$ conducted a few decades back had reported service-related factors such as availability, accessibility and affordability of eye care services to be the major barrier to utilization of eye care services in contrast to the social-related barrier found in this study. This suggests a change in trend in barriers to eye care services utilization over time. Social engagement/other priorities were reported to be the primary barrier to eye care utilization in this study. This conflicts with the studies by Ebeigbe, Ovenseri-Ogbomo \&Kimani.,, ${ }^{715}$ in which lack of felt need and lack of finance respectively, were reported to be the most common barrier to utilization of eye care services. People tend to put other things they consider important like work or school ahead of seeking eye care especially when the ocular conditions are not discomforting. As such visiting the hospital for an eye problem is generally placed very low on the priority list of most people unless the need to seek eye care becomes urgent.

The person-related barrier category was the second commonest category of barrier reported in this study. Ability to perform daily task with condition, no perceived need for eye care services and acceptance of the condition were the commonest person-related barriers reported. Less importance is often placed visual problems especially asymptomatic conditions such as glaucoma by individuals. Even when symptomatic, symptoms are usually not considered problems until the individual cannot perform visual tasks. When individuals with ocular conditions are able to go about their day to day activities without significant discomfort, the perceived need for eye care services become very low. They are only moved to seek treatment when symptoms become unbearable. Dhaliwal, Gupta and Patel et al. ${ }^{16,17}$ reported person-related (attitude) barriers to be major barriers to utilization of eye care services in Indians. A study in southern India by Marmamula et al. ${ }^{18}$ reported the lack of perceived need for eye care services to be the leading person-related barrier to utilization of eye care services. Other studies have reported similar findings. ${ }^{10,19-21}$

The cost of eye care services and transportation to eye care facilities were the major financial barriers reported in the study. Financial barriers are well-established barriers to eye care and health care in general and has been reported by several studies. ${ }^{10,11,15,17,19,20,22}$ In a similar study in the region, cost of surgery was identified by $91 \%$ of the respondents as the most important barrier to cataract surgery utilization in the Upper East region. ${ }^{19}$ Studies have established positive correlation between reduction in cost of service and uptake of eye care services. In a study by Ellwein et al. ${ }^{23}$ a reduction in the cost of cataract surgery and provision of travel expenses resulted in a significant increase in the utilization of cataract surgery in India. Cost of eye care service as a barrier to utilization is also demonstrated by the fact that individuals with insurance coverage generally have better eye care seeking behaviour than those without insurance coverage. ${ }^{24,25}$ The studies of Elliot et al. and Zhang et al. ${ }^{26,27}$ reported having no insurance coverage and the cost of service as major barriers to utilization of eye care services.

Contrary to the study of Gyasi et al., ${ }^{19}$ fear was not a major barrier to eye care services utilization in this study. Gyasi et al. ${ }^{19}$ reported fear to be the third most common barrier to uptake of cataract surgery in the Upper East region. Again, contrary to other studies in the region, distance to eye care facility was a significant barrier to utilization of eye care services in this study. In the study by Gyasi et al. ${ }^{19}$ to access the barriers to the uptake of cataract surgery in the Upper East region, none of the participants reported the distance to eye care facilities as 
a form of barrier to them. A significant number of the participants reported having no knowledge of the availability of eye care services or thinking nothing could be done about ocular conditions they have. Low levels of knowledge of eye care services have the potential of resulting in high prevalence of use of alternative sources of care including traditional healers and patent medicine sellers. ${ }^{28}$ This emphasizes the importance of education of the general public about eye conditions, availability of treatment and eye care services.

\section{Conclusion}

As barrier trends shift more towards factors such as social engagement/other priorities, ability to perform daily task with condition and lack of knowledge of the availability of eye care services and treatment, new and more intensive awareness campaigns are needed to bring about changes in behavior or attitude among individuals to improve utilization of available eye care services. With cost of service still a significant barrier to eye care services utilizations in the region, the National Health Insurance Scheme (NHIS) should be made operational at all community levels and expanded to cover a wider range of eye care services.

\section{Funding details}

None.

\section{Acknowledgements}

None.

\section{Conflicts of interest}

Authors declare that there is no conflict of interest.

\section{References}

1. WHO. Visual impairment and blindness. Geneva: World Heal Organization. 2013. p. 1.

2. Ramke J, Zwi AB, Palagyi A, et al. Equity and Blindness: Closing Evidence Gaps to Support Universal Eye Health. Ophthalmic Epidemiol. 2015;22(5):297-307.

3. Kovai V, Krishnaiah S, Shamanna BR, et al. Barriers to accessing eye care services among visually impaired populations in rural Andhra Pradesh, South India. Indian J Ophthalmol. 2007;55:365-371.

4. Pollard TL, Simpson JA, Lamoureux EL, et al. Barriers to accessing low vision services. Ophthalmic Physiol Opt. 2003;23(4):321-327.

5. Ebeigbe JA, Ovenseri-Ogbomo GO.Barriers To Utilization Of Eye Care Services In Rural Communities In Edo State, Nigeria. Bo Med J. 2014;11:98-104.

6. GSS. Population and Housing Census: Regional Analytical Report. 2010. p. 3.

7. Ebeigbe JA, Ovenseri-Ogbomo GO. Barriers To Utilization Of Eye Care Services In Rural Communities In Edo State, Nigeria. Bo Med J. 2014;11:98-104.

8. Robin AL, Nirmalan PK, Krishnadas R, et al. The utilization of eye care services by persons with glaucoma in rural south India. Trans Am Ophthalmol Soc. 2004;102:47-54

9. Olusanya BA, Ashaye AO, Owoaje ET, et al. Determinants of Utilization of Eye Care Services in a Rural Adult Population of a Developing Country. Middle East Afr J Ophthalmol. 2016;23(1):96-103.
10. Palagyi A, Ramke J, Du Toit R, et al. Eye care in Timor-Leste:A population-based study of utilization and barriers. Clin Exp Ophthalmol. 2008;36(1):47-53

11. Kovai V, Krishnaiah S, Shamanna BR, et al. Barriers to accessing eye care services among visually impaired populations in rural Andhra Pradesh, South India. Indian J Ophthalmol. 2007;55(5):365-371.

12. Dandona R, Dandona L, Naduvilath TJ, et al. Utilisation of eyecare services in an urban population in southern India:the Andhra Pradesh eye disease study. Br J Ophthalmol. 2000;84(1):22-27.

13. Brilliant GE, Lepkowski JM, Zurita B, et al. Social determinants of cataract surgery utilization in south India. The Operations Research Group. Arch Ophthalmol. 1991;109(4):584-589.

14. Vaidyanathan K, Limburg H, Foster A, et al. Changing trends in barriers to cataract surgery in India. Bull World Health Organ. 1999;77(2):104 109

15. Kimani K, Karimurio J, Gichuhi S, et al. Barriers to utilization of eye care services in Kibera and Dagoreti, Kenya. JOECSA. 2013;14(2):5561.

16. Patel D, Baker H, Murdoch I. Barriers to uptake of eye care services by the Indian population living in Ealing, west London. Health Educ J. 2006;65:267-276.

17. Dhaliwal U, Gupta SK. Barriers to the uptake of cataract surgery in patients presenting to a hospital. Indian J Ophthalmol. 2007;55(2):133136.

18. Marmamula S, Khanna RC, Shekhar K, et al. A population-based cross-sectional study of barriers to uptake of eye care services in South India:the Rapid Assessment of Visual Impairment (RAVI) project. BMJ Open. 2014;4(6):e005125.

19. Gyasi M, Amoaku W, Asamany D. Barriers to cataract surgical uptake in the upper East region of ghana. Ghana Med J. 2007;41(4):167-170.

20. Chandrashekhar TS, Bhat HV, Pai RP, et al. Coverage, utilization and barriers to cataract surgical services in rural South India:Results from a population-based study. Public Health. 2007;121(2):130-136.

21. Ashaye A, Ajuwon AJ, Adeoti C. Perception of blindness and blinding eye conditions in rural communities. J Natl Med Assoc. 2006;98(6):887893

22. Chou CF, Sherrod CE, Zhang X, et al. Barriers to eye care among people aged 40 years and older with diagnosed diabetes, 2006-2010. Diabetes Care. 2014;37(1):180-188.

23. Ellwein LB, Lepkowski JM, Thulasiraj RD, et al. The cost effectiveness of strategies to reduce barriers to cataract surgery. The Operations Research Group. Int Ophthalmol. 1991;15(3):175-183.

24. Harmon C, Nolan B. Health insurance and health services utilization in Ireland. Health Econ. 2001;10(2):135-145.

25. Gnawali DP, Pokhrel S, SiéA, et al. The effect of community-based health insurance on the utilization of modern health care services:Evidence from Burkina Faso. Health Policy (New York). 2009;90(2-3):214-222.

26. Elliott AF, Chou CF, Zhang X, et al. Eye care utilization among women aged 40 years with eye diseases in 19 states, 2006-2008. Morbisity Mortal Wkly Rep. 2010;59(19):588-591.

27. Zhang X, Lee PP, Thompson TJ, et al. Health insurance coverage and use of eye care services. Arch Ophthalmol. 2008;126(8):1121-1126.

28. Ntim-Amponsah C, Amoaku W, Ofosu-Amaah S. Alternate eye care services in a ghanaian district. Ghana Med J. 2005;39(1):19-23. 